\title{
AUTONOMOUS AND REMOTELY OPERATED VEHICLE TECHNOLOGY \\ FOR HYDROTHERMAL VENT DISCOVERY, EXPLORATION, AND SAMPLING
}

BY DANA R. YOERGER, ALBERT M. BRADLEY, MICHAEL JAKUBA,

CHRISTOPHER R. GERMAN, TIMOTHY SHANK, AND MAURICE TIVEY

Autonomous and remotely operated underwater vehicles play complementary roles in the discovery, exploration, and detailed study of hydrothermal vents. Beginning with clues provided by towed or lowered instruments, autonomous underwater vehicles (AUVs) can localize and make preliminary photographic surveys of vent fields. In addition to finding and photographing such sites, AUVs excel at providing regional context through fine-scale bathymetric and magnetic field mapping. Remotely operated vehicles (ROVs) enable close-up inspection, photomosaicking, and tasks involving manipulation of samples and instruments. Increasingly, ROVs are used to conduct in situ seafloor experiments. ROVs can also be used for fine-scale bathymetric mapping with excellent results, although AUVs are usually more efficient in such tasks.
We have used AUV and ROV technologies in a complementary fashion, inspired in part by the success of our coordinated operations with the Autonomous Benthic Explorer $(A B E)$ and the human-occupied submersible Alvin (Shank et al., 2003) (Figure 1). Originally, we operated the AUV ABE and ROV Jason/Medea separately, either on different cruises or in different time slots on the same cruise. We have begun operating them simultaneously, making more productive use of valuable ship time. Key technical elements of simultaneous operations include managing multi-vehicle launch and recovery, compatible navigation systems, and the ability to leave the AUV unattended while the ROV works in another, perhaps distant, area. We have also found that an additional ability of the AUV to anchor when its mission ends before the ROV is recovered is very useful. By anchoring, the AUV remains safe in a knownposition without forcing a premature end to the ROV dive. 

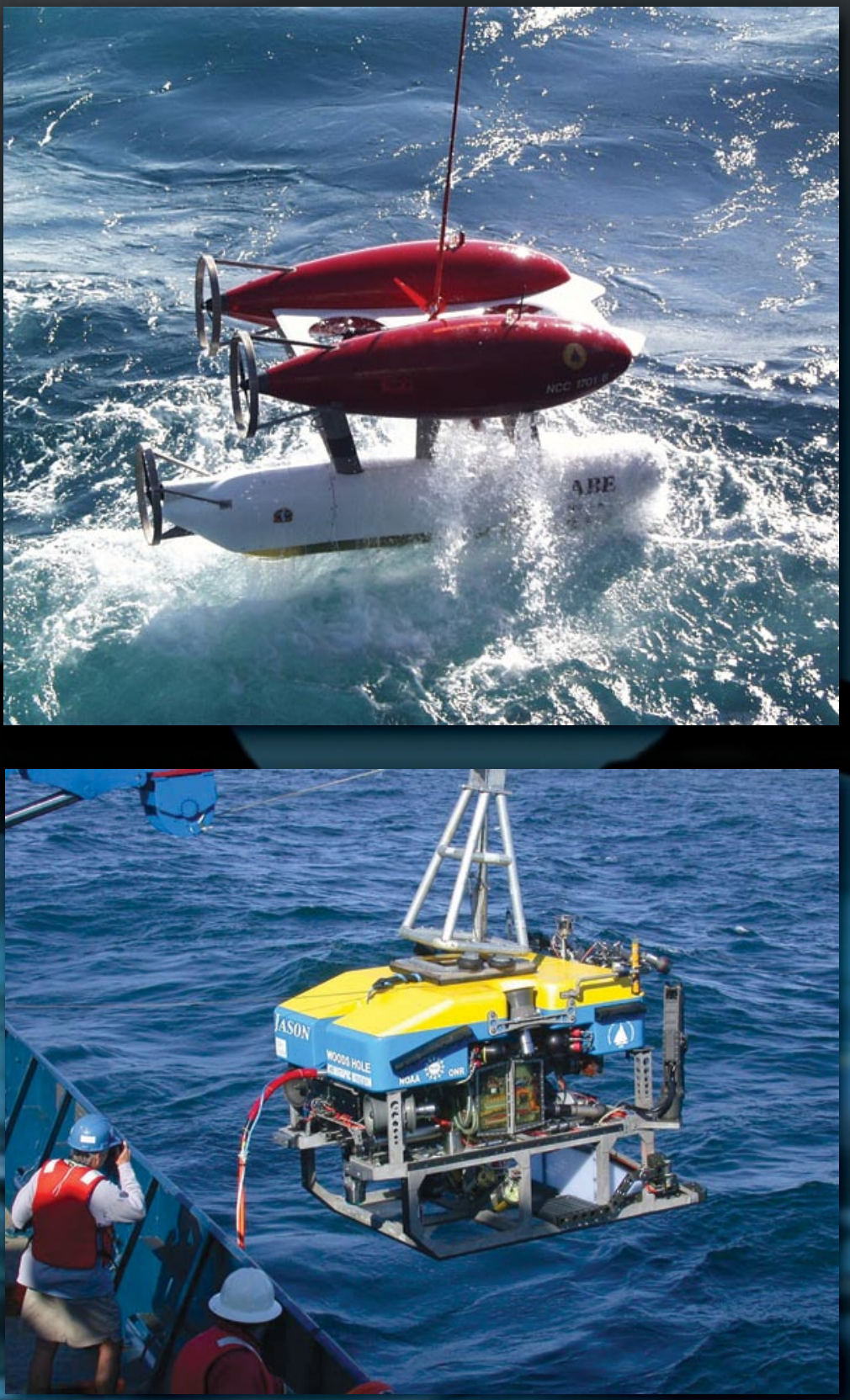

Figure 1. Operations of the Autonomous Benthic Explorer ( $A B E$, shown on the top) locate vent sites, provide detailed bathymetric and magnetic field maps of the surrounding areas, and photograph the vent sites themselves. Based on this information, ROVs like Jason (bottom) can be directed to inspect the sites up close, obtain many types of samples, and conduct in situ experiments. 
Autonomous Benthic Explorer ( $A B E$ )

$A B E$ operates independently from the support research vessel after launch. It has no tether, is controlled in real time by onboard computers, does not require navigation updates or communication with the surface vessel, and uses its own rechargeable batteries for all power. from sea-surface motion. Both Medea and Jason are designed to operate to a maximum depth of $6,500 \mathrm{~m}$ and have been operated from a variety of vessels. Jason is connected to Medea by a neutrally buoyant tether, while Medea is connected to the surface with a standard oceanographic fiber-optic,

\section{AUVs and ROVs are powerful tools \\ for hydrothermal-vent discovery, exploration, and sampling.}

During a dive, $A B E$ uses acoustic longbaseline transponder navigation together with bottom-lock acoustic Doppler measurements to determine its position and velocity over the seafloor. A dive can consist of any mix of water-column investigations at constant depth, seafloor geophysical investigations at fixed heights (50-200 m) above the seafloor, and digital photography within a few meters above the seafloor. $A B E$ usually surveys until either it reaches the end of its programmed survey or its batteries are depleted, typically between 20-30 km along track and 15-30 hours of survey time, depending on sensor payload, survey type, and terrain. $A B E$ is rated to $4500 \mathrm{~m}$ depth and has completed 199 deep-ocean dives to an average depth over $2000 \mathrm{~m}$.

\section{Jason/Medea}

Jason/Medea is an ROV system designed for scientific investigation of the deep seafloor. Medea serves in a tethermanagement role that decouples Jason steel-armored cable.

Jason is designed for both mapping and sampling tasks. It features a navigation system based on long-baseline acoustic transponders, a Doppler velocity log, and a north-seeking, fiber-optic compass that is fully coupled with Jason's control system to provide a variety of automated control modes. Jason's sampling capability is based on an integrated system consisting of two spatially correspondent manipulator arms, reconfigurable sample storage, and carefully positioned cameras and lights.
We have used the combination of AUV and ROV to discover, explore, and sample deep-sea hydrothermal vents as well as other marine geological phenomena. On a series of cruises, we have used the AUV to locate and make preliminary surveys of the vent fields, after which ROVs were used for detailed inspection and sampling (Table 1).

\section{USING AUVS TO LOCATE AND CHARACTERIZE HYDROTHERMAL SITES}

Active hydrothermal sites are typically located by detecting the hydrothermal plumes found in the overlying water column. These plumes occur when seawater circulates through oceanic crust, becomes heated through interaction with the host rock at depth to become a super-heated, buoyant, and highly reactive fluid (see Tivey, this issue). After emerging from the seafloor at a hydrothermal vent site, the resulting hot, chemically altered water rises vigorously in a narrow column. Through entrainment of the surrounding seawater, the vent plumes spread horizontally and become more dilute. They rise until their density reaches that of the ambient seawater (typically 100-300 $\mathrm{m}$ above the seafloor),

DANA R. YOERGER (dyoerger@whoi.edu) is Associate Scientist, Department of Applied Ocean Physics and Engineering, Woods Hole Oceanographic Institution, Woods Hole, MA, USA. ALBERT M. BRADLEY is Principal Engineer (retired), Department of Applied Ocean Physics and Engineering, Woods Hole Oceanographic Institution, Woods Hole, MA, USA. MICHAEL JAKUBA is Postdoctoral Investigator, Department of Applied Ocean Physics and Engineering, Woods Hole Oceanographic Institution, Woods Hole, MA, USA. CHRISTOPHER R. GERMAN is Senior Scientist, Department of Geology and Geophysics, Woods Hole Oceanographic Institution, Woods Hole, MA, USA. TIMOTHY SHANK is Associate Scientist, Department of Biology, Woods Hole Oceanographic Institution, Woods Hole, MA, USA. MAURICE TIVEY is Associate Scientist, Department of Geology and Geophysics, Woods Hole Oceanographic Institution, Woods Hole, MA, USA. 
Table 1. Summary of cruises that have featured coordination of $A B E$ and ROV operations

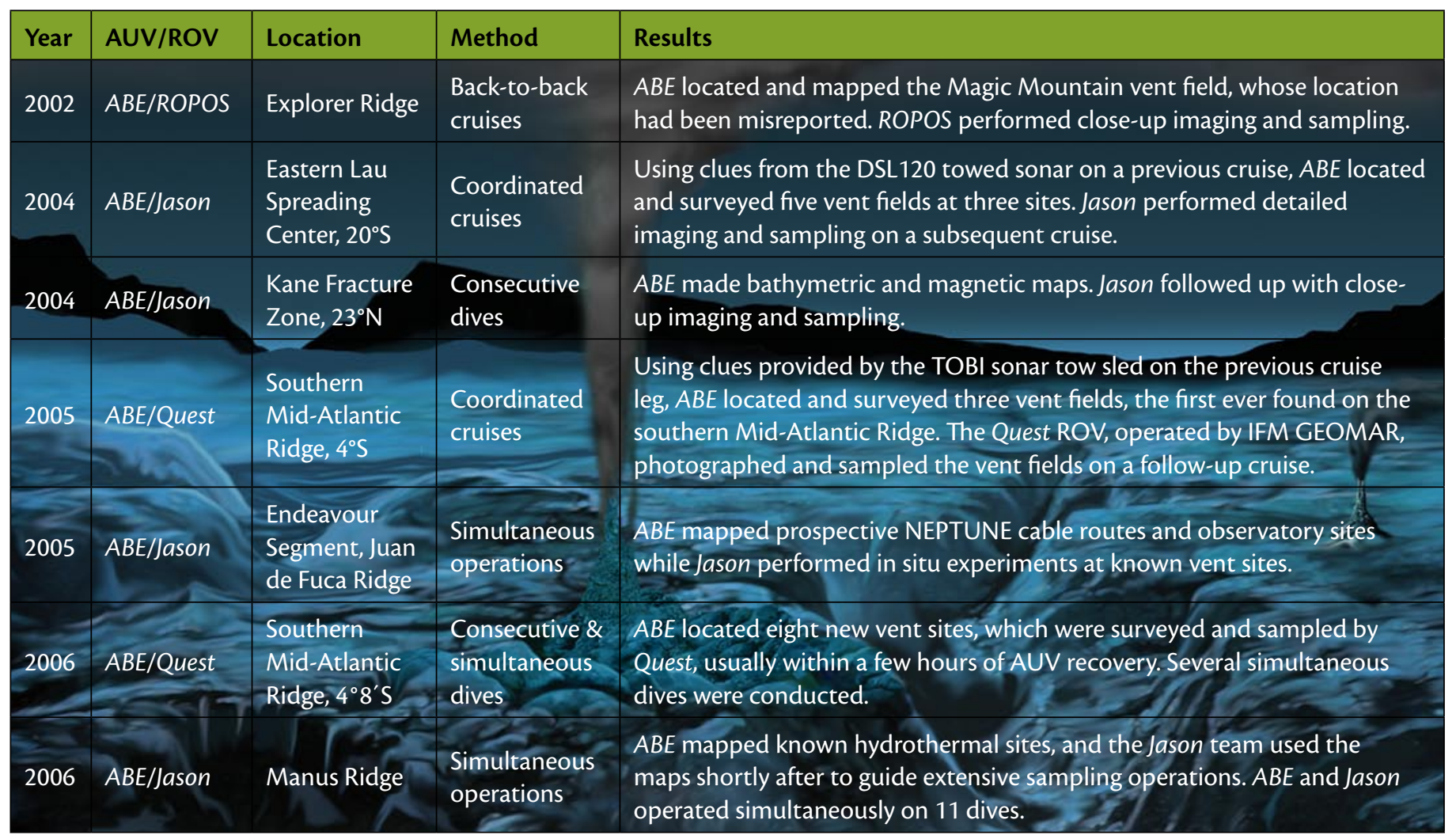

after which the anomalous fluid is advected by local currents and self-imposed pressure gradients. The resulting nonbuoyant layer of altered water, analogous to the smog layer above a polluted city, typically spreads over an area many kilometers across and has a thickness on the order of 100 meters.

\section{Three-Phase Survey Approach}

We have localized hydrothermal vents at sites in the Eastern Lau Spreading Center $\left(21^{\circ} 08^{\prime} \mathrm{S}, 175^{\circ} 12^{\prime} \mathrm{W}\right)$ and the southern Mid-Atlantic Ridge ( $7^{\circ} 57^{\prime} \mathrm{S}, 14^{\circ} 22^{\prime} \mathrm{W}$ ) using an approach designed by our scientific collaborators (German et al.,
2004; German et al., 2005) that exploits the structure of typical plumes. The AUV survey begins after the nonbuoyant layer has been located with a towed instrument, most often by a sonar sled equipped with instruments to detect regions with high optical backscatter or anomalous temperature (Martinez et al., 2004). Our localization technique features three successive phases, each consisting of a grid survey at successively lower height and finer trackline spacing. These phases reflect the structure of the plume: the first phase is conducted in the nonbuoyant plume where the plume signature will be spread over the largest area. The second phase seeks to intercept the column of rising vent fluids while making a detailed bathymetric and magnetic field map of the area. In the third phase, the vent site itself is photographed. Figure 2 summarizes the three-phase approach, showing data from a series of dives on the Kilo Moana site in the Eastern Lau Spreading Center. Figure 3 illustrates Phase 3 survey results from the southern Mid-Atlantic Ridge, including digital imagery and the performance of the vehicle in following the seafloor while avoiding obstacles. 


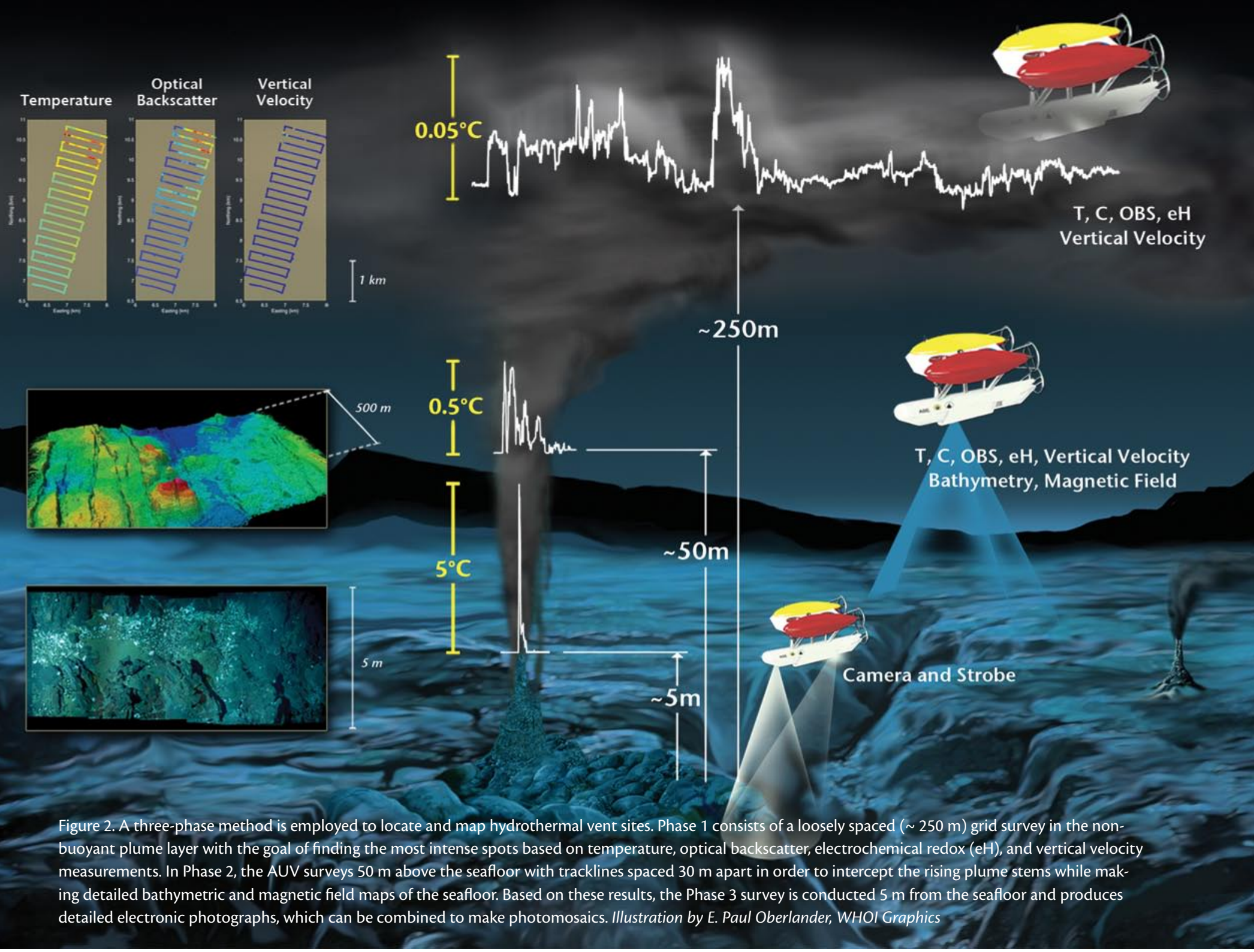

\section{Position Estimation/Navigation}

The AUV must maintain an accurate estimate of its position during all phases.

In Phase 1, the position estimate should be accurate on the order of $\sim 50 \mathrm{~m}$ or better, which will permit the Phase 2 tracklines to be planned to intercept the rising plumes. Presently, $A B E$ 's position estimate based on long-baseline transponders is typically repeatable in the same transponder net to a few meters. For Phase 2, position estimates should be sufficiently precise to enable the bathymetric map to be assembled (typically on the order $2 \mathrm{~m}$ ), although the bathymetric data itself can be used to improve relative positioning between tracklines (Roman and Singh, 2005). For Phase 3, navigational precision should be sufficient to enable close trackline spacing on the order of $5 \mathrm{~m}$ or less if complete coverage is desired.

\section{Plume Tracers}

For all phases, the scientific sensor suite carried by the AUV is critical. We have had success using combinations of optical backscatter, potential temperature, vertical temperature gradient, reductionoxidization potential (eH) (Nakamura et al., 2000), and several techniques for estimating vertical flow rates to detect the presence of hydrothermal plumes. For the Phase 2 and occasionally Phase 1 surveys, rising plume fluids push the vehicle up despite the best efforts of the AUV control system to maintain constant depth. We have used a dynamic model to infer the vertical velocity that induced the depth perturbation, which compared favorably to measurements from an onboard acoustic current meter. 

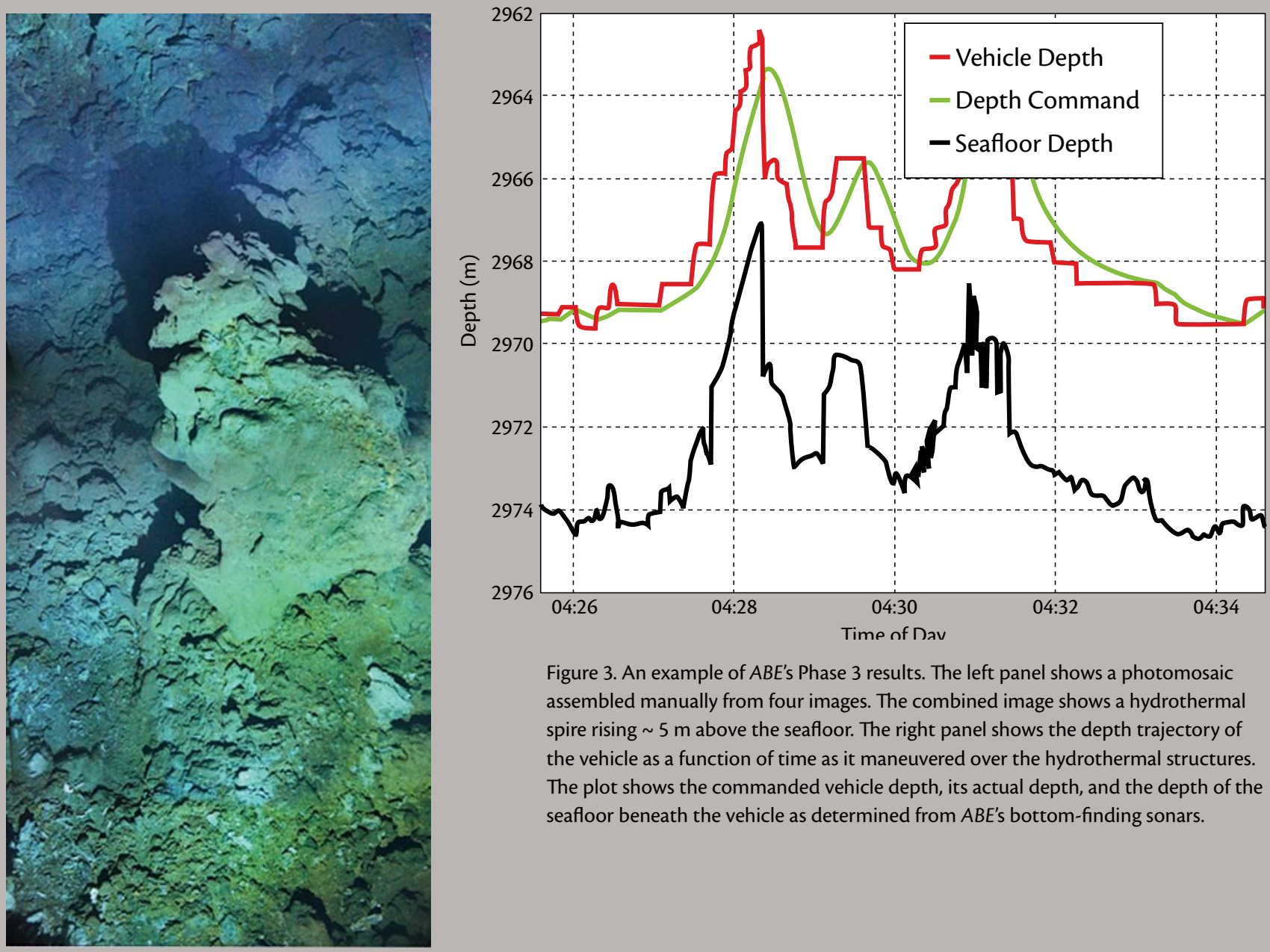

Figure 3. An example of ABE's Phase 3 results. The left panel shows a photomosaic assembled manually from four images. The combined image shows a hydrothermal spire rising $\sim 5 \mathrm{~m}$ above the seafloor. The right panel shows the depth trajectory of the vehicle as a function of time as it maneuvered over the hydrothermal structures. The plot shows the commanded vehicle depth, its actual depth, and the depth of the seafloor beneath the vehicle as determined from ABE's bottom-finding sonars.

\section{Automated Nested Survey}

An AUV can use its onboard computing power to react to data acquired during the survey to improve the yield from each dive. A number of approaches have been proposed and a few implemented for these types of problems, including biomimetic approaches inspired by creatures that track odors such as moths. Our method is based on more conventional mapping techniques. The vehicle first performs a conventional grid pattern over the entire site, then executes additional focused surveys at the most promising sites (Jakuba et al., 2005; Yoerger et al., 2007). During the conventional grid survey, the vehicle maintains multiple, fixed-length, sorted lists of hydrographic measurements classified as indicative of hydrothermally altered water based on $\mathrm{eH}$ and temperature. The anomalous readings in the lists are then grouped according to location using a clustering algorithm. The algorithm then assigns a scalar value to each cluster that represents the relative value of revisiting areas of interest. Following completion of the conventional grid survey, sites ranked highly are revisited based on their scores. While we have used this approach successfully in real time for Phase 3 surveys, post-dive analysis shows it would be effective for Phase 2 dives as well. We believe our approach is also a precursor to fully automated discovery, where a vent field could be located and surveyed in a single AUV dive.

We have taken advantage of this approach for Phase 3 photo surveys at sites in the Eastern Lau Spreading Center and the southern Mid-Atlantic Ridge with good success. Figure 4 shows results 
from a southern Mid-Atlantic Ridge site. In our Eastern Lau Spreading Center survey, revisiting the site with the highest score extended survey time by only 5 percent, while increasing the number of photographs containing vent fauna by 36 percent. Figure 4 shows the conventional and adaptive survey tracks as well as the clusters of identified anomalies and their ranking.

In each case, $A B E$ 's vent discoveries were followed up with ROV dives for more detailed survey and sampling. This synergism will be presented in more detail in a later section.

\section{ROV SURVEY, SAMPLING, AND IN SITU EXPERIMENTATION}

Guided by skilled human pilots on the surface using high-quality video imagery, navigational instruments, and sonars,
ROVs are able to work in complicated sites with hazards that include complex terrain and hot, caustic vent fluids. With continuous power and high-speed telemetry offered by their cables, ROVs can operate continuously for days. The Jason ROV (Figure 1), operated by the Woods Hole Oceanographic Institution, is an example of an ROV designed specifically for scientific operations on the deep seafloor.

ROVs are often used for mapping and are especially effective for close-up, fine scale sonar or photographic surveys where human supervision can improve safety and effectiveness and the restrictions on vehicle movement caused by the tether are not severe. ROVs can also produce excellent results for broaderscale surveys, although the vehicle tether limits speed.
An ROV's human pilots can be aided by a number of control system enhancements that improve productivity and reduce operator fatigue. These include navigational displays that show the ROV in relation to known targets and the surrounding bathymetry, and closed-loop systems that automatically control vehicle heading, depth, and position. While auto heading and depth controls have been common in ROVs nearly since their inception, closed-loop position control (akin to a vessel's dynamic positioning system) is a more recent innovation, enabled in large part by reliable algorithms and motion sensing using bottomlock Doppler navigators (Kinsey and Whitcomb, 2004). Jason's pilots estimate that they use the closed-loop position approximately 20-40 percent of the time on the seafloor, depending on the task

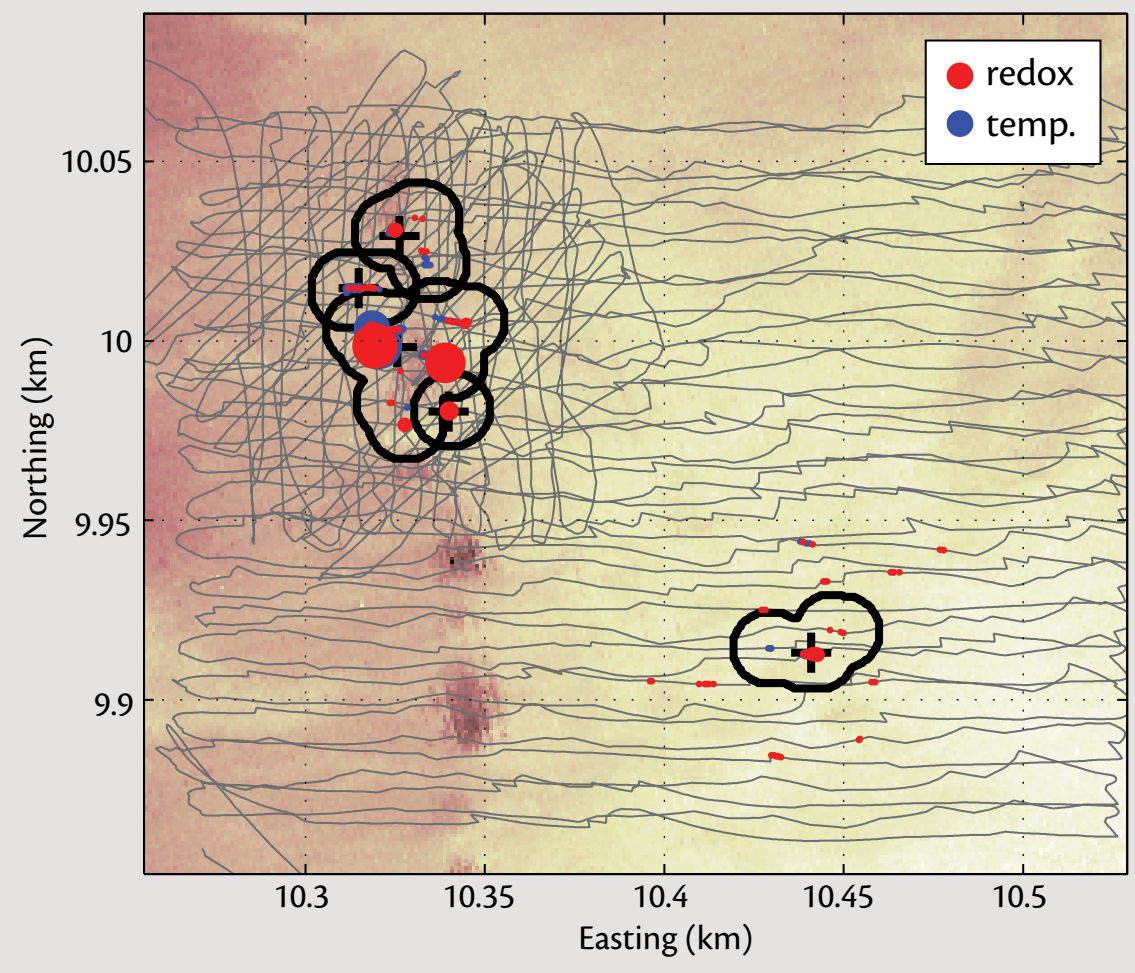

Figure 4. Example of conventional and automated nested surveys on a Phase 3 survey from the first AUV/ROV cruise to the southern Mid-Atlantic Ridge. $A B E$ performed a grid survey with east-west lines spaced 5 meters apart, while keeping track of the most promising areas for further detailed survey. The plot shows the targets identified and their priorities, along with anomalies in $\mathrm{eH}$ and temperature. The north-south and diagonal tracks in the northwest corner formed the automated, nested part of the survey that was executed autonomously following the conventional survey. On further investigation by the Quest ROV, the site with the highest ranking had the highest temperature ever measured at a hydrothermal vent.

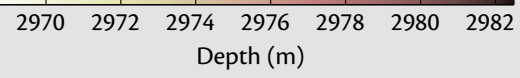


and the preferences of the pilot.

ROVs offer broad sampling capabilities that can vary significantly from cruise to cruise. On a recent voyage to the Manus Basin ( $\left.3^{\circ} 45^{\prime} \mathrm{S}, 151^{\circ} 29^{\prime} \mathrm{W}\right)$, Jason took extensive samples, including mineralized vent chimneys and volcanic host rock, along with high-temperature vent fluids at in situ pressure. Fluid samplers vary in sophistication from Niskin bottles to gas-tight devices that keep the sample at ambient pressure to preserve dissolved gasses. On other cruises, biological samples are taken using manipulators and specialized devices such as suction samplers designed to capture small animals and microbial material, nets for larger animals, and "mussel pots" to collect all benthic animals in a prescribed area. If sediment sampling is required, ROVs can operate a variety of devices such as tube and box corers. ROVs can also operate rock drills to recover rock cores and to establish sites for in situ experiments.

\section{COMBINED AUV AND ROV OPERATIONS}

Recently, we have begun exploiting the synergism between AUVs and ROVs to increase the overall yield from a cruise and to improve the quality of our results. In some cases, the two vehicle types have different goals and the improvement arises from our ability to have both vehicles working on the seafloor at the same time. As an example, in 2005 we mapped portions of the Endeavour segment of the Juan de Fuca Ridge ( $47^{\circ} 55^{\prime} \mathrm{N}, 129^{\circ} 6^{\prime} \mathrm{W}$ ) with $A B E$ while Jason installed seafloor experiments in previously discovered vent fields. In most cases, however, we operate the vehicles cooperatively, using the AUV as a scout to make maps and to discover the areas of highest interest after which the ROV visits the most promising sites using the AUV-generated maps as real-time guides.

In another example, Figure 5 shows results from our recent Manus Basin cruise. We generated the bathymetric map from data gathered by $A B E$ over several dives, then overlaid the subsequent ROV Jason tracklines. Using a realtime display similar to that shown in the figure, the science party and the Jason operational team were able to identify the most interesting spots and drive Jason to them. In addition to quickly acquiring promising sampling sites, the interactive map display also allows the pilots to anticipate or avoid particularly hazardous terrain, which yields im-

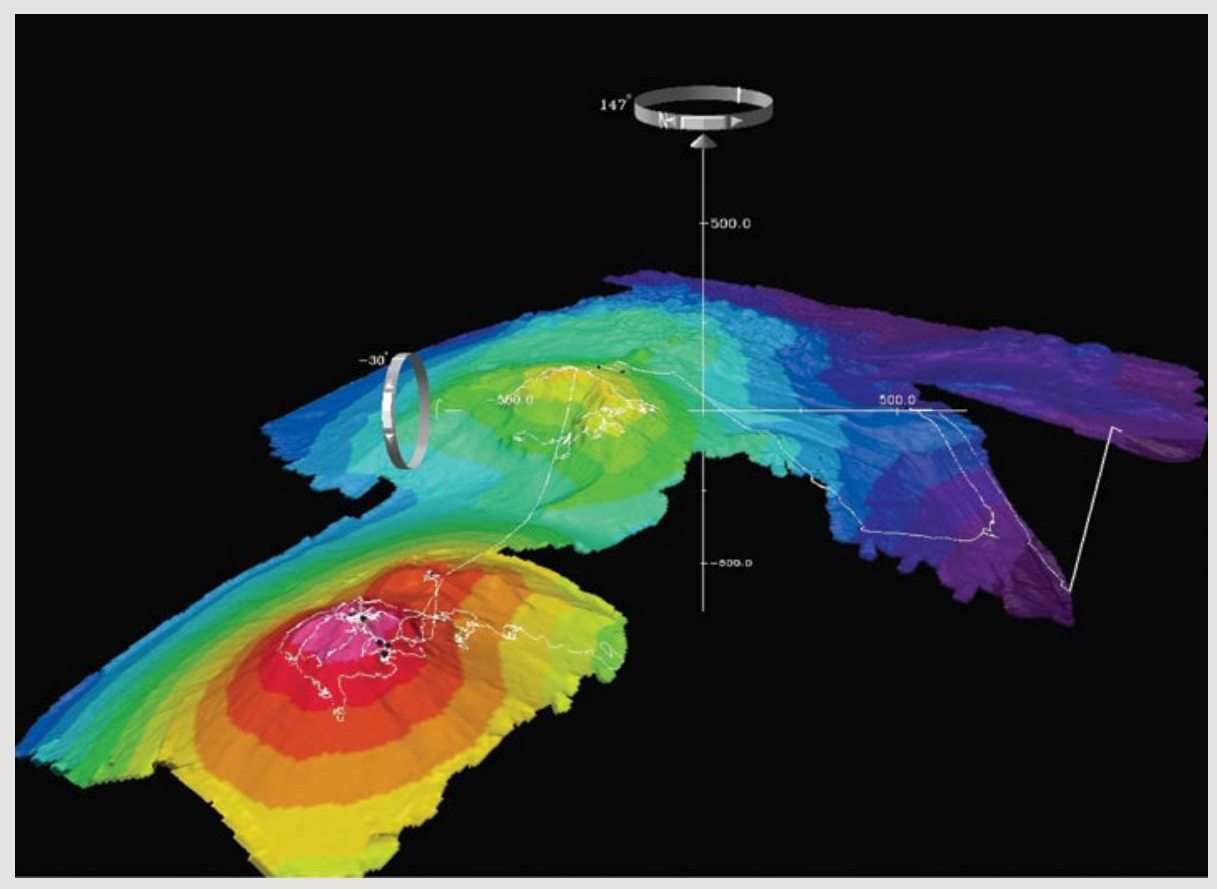

Figure 5. Interactive display used in real time during Jason dives. The bathymetric data was assembled from four $A B E$ dives. The real-time overlay of Jason tracklines permits the pilots and observers to plan the vehicle path based on fine-scale features imaged by $A B E$. The display can be rotated, translated, and zoomed in real time. Figure created using Fledermaus software 
proved safety and productivity.

In some cases, we conducted the AUV and ROV dives in a tightly coupled fashion. Following an AUV recovery, the vessel would be repositioned and the ROV launched. As the ROV descended, we reprocessed the AUV's real-time navigation, processed the multibeam data, and built a preliminary bathymetric map. These results were ready as the ROV reached the seafloor for insertion into the real-time ROV navigation display.

Operating AUVs and ROVs simultaneously provides many advantages, but places additional requirements on both systems, including those for navigation and launch/recovery logistics.

\section{Navigation}

Each vehicle must navigate without substantially interfering with the other. $A B E$ and Jason presently rely heavily on longbaseline acoustic navigation, and our current scheme does not directly support multiple vehicle operations. We have had success with allowing the AUV to interrogate the transponder net on its normal
$A B E$ 's long-baseline acoustic navigation algorithm (Yoerger et al., 2007) prevented any significant problems. The ROV then relied primarily on its Doppler navigator and north-seeking gyrocompass to keep track of its movements. Ongoing developments will enable multiple vehicles to directly access the long-baseline net while reducing the reliance on transponder navigation though the use of synchronous beacons, Doppler/inertial systems, and ultrashort-baseline (USBL) navigation from the vessel. In a recent cruise to the southern Mid-Atlantic Ridge, we operated $A B E$ simultaneously with the Quest ROV operated by IFMGEOMAR. $A B E$ used its long-baseline transponder system for positioning while Quest fixes were obtained using a USBL system with minimal interference.

\section{Launches}

When possible, we prefer to launch the AUV first, then the ROV. This sequence allows the vessel to be positioned over the starting point of the AUV survey and eliminates the possibility of entangle-

\section{When used in coordinated fashion, AUVs}

\section{and ROVs provide improved efficiency and higher-quality results.}

10-second period, while occasionally allowing the ROV to get a few fixes using a different interrogation interval. While some AUV fixes were lost when acoustic returns overlapped, the robustness of ment with the main ROV cable during descent. However, the complexities of cruise scheduling often require us to launch the AUV while the ROV is operating. In this case, we program the AUV to drive away from the vessel several hundred meters during its initial descent. In some cases, the ROV operating position can be far from the AUV survey starting position. We have programmed $A B E$ to transit over a kilometer during its descent, and then drive a connector leg several kilometers in length to the desired starting point. While conceptually straightforward, this approach presents several problems, including initializing the AUV at a position not known until launch time and directing the vehicle to transit substantial distances before it reaches sufficient depth for its transponder navigation solution to be valid (approximately $500 \mathrm{~m}$ ). Our approach relies on dead reckoning when no longbaseline fixes are available.

\section{Recoveries}

At the end of most AUV surveys, the vehicle drops its ascent weights and returns to the surface. This is unsatisfactory when an AUV is operating simultaneously with an ROV, especially when ROV operations may be some distance away from the AUV survey location. Unless the ROV dive is interrupted and the ROV recovered immediately, the AUV could spend a long time on the surface, drifting with the currents. To avoid these circumstances, $A B E$ can anchor to the seafloor when the survey ends and waits for an acoustic command before returning to the surface. In addition to enabling more effective simultaneous operations, the anchoring system also improves safety when the vessel leaves the site to conduct other operations out of acoustic contact with the AUV. In the past, we have conducted CTD and vessel multibeam surveys, Alvin submersible dives, and towed sonar sur- 
veys in this fashion. Should the AUV dive end earlier than expected or if the vessel is delayed in picking it up, the AUV will anchor until the vessel returns.
Bach. We also acknowledge the ROV expedition leaders: Andrew Bowen, Will Sellers, Matthew Heintz, and Christian Seiter. The $A B E$ operational teams in-

\section{Each step forward provided increased}

operational and technical challenges but
also improved efficiency and results.

\section{CONCLUSIONS}

AUVs and ROVs are powerful tools for hydrothermal-vent discovery, exploration, and sampling. AUVs excel at survey, mapping, and localization tasks at a variety of scales from kilometers to meters. ROVs excel at working in rough terrain around and within vent sites for detailed survey mapping ( $100 \mathrm{~m}$ scales), sampling, photography, and in situ experiments. When used in coordinated fashion, AUVs and ROVs provide improved efficiency and higher-quality results. Our initial efforts used the vehicles on separate but coordinated cruises, advanced to consecutive dives on a single cruise, and presently we can operate both vehicles simultaneously with appropriate planning. Each step forward provided increased operational and technical challenges but also improved efficiency and results.

\section{ACKNOWLEDGEMENTS}

We would like to thank the chief scientists from the cruises discussed here, including Robert Embley, Charles Langmuir, John Delaney, Deborah Kelley, Andrea Koschinsky, and Wolfgang cluded Rodney Catanach, Alan Duester, and Andrew Billings. Special thanks to Ko-Ichi Nakamura for the use of his $\mathrm{eH}$ sensor and to Vicki Ferrini for the combined ABE/Jason navigational display. $A B E$ and Jason field operations have been supported by the National Science Foundation, the National Oceanic and Atmospheric Administration Office of Ocean Exploration, the UK Natural Environment Research Council, Deutsche Forschungsgemeinschaft, and Nautilus Minerals, Inc. 菂

\section{REFERENCES}

German, C.R., D.P. Connelly, R.D. Prien, D.R. Yoerger, M. Jakuba, A.M. Bradley, T. Shank, H. Edmonds, and C.H. Langmuir. 2004. New techniques for hydrothermal exploration: In situ chemical sensors on AUVs_- Preliminary results from the Lau Basin. Eos, Transactions, American Geophysical Union 85(47), Fall Meeting Supplement, Abstract B13A-0190.

German, C.R., D.P. Connelly, R.D. Prien, D.R. Yoerger, M. Jakuba, A.M. Bradley, T. Shank, K. Nakamura, C.H. Langmuir, and L.M Parsons. 2005. New techniques for hydrothermal plume investigation by AUV. Geophysical Research Abstracts 7, European Geosciences Union, Abstract EGU05-A-04361.

Jakuba, M., D.R. Yoerger, A. Bradley, C. German, C. Langmuir, and T. Shank. 2005. Multiscale, multimodal AUV surveys for hydrothermal vent localization. Proceedings of the Fourteenth International Symposium on Unmanned Untethered Submersible Technology(UUST05), Durham, NH.

Kinsey, J.C., and L.L. Whitcomb. 2004. Preliminary Field Experience with the DVLNAV Integrated Navigation System for Oceanographic Submersibles. Control Engineering Practice 12(12):1,541-1,549.

Martinez, F., B. Taylor, J.A. Resing, E. Baker, S.L. Walker, and G.J. Massoth. 2004. Geophysical and hydrothermal survey of the Lau Basin Integrated Studies Site. Eos, Transactions, American Geophysical Union 85(47), Fall Meeting Supplement, Abstract B13A-0188.

Nakamura, K., S. Veirs, C.P. Sarason, R.E. McDuff, F. Stahr, D.R. Yoerger, and A.M. Bradley. 2000. Chemical signals in rising buoyant plumes and tidally oscillating plumes at the Main Endeavour vent field, Juan de Fuca Ridge. Eos, Transactions, American Geophysical Union 81, Fall Meeting Supplement, Abstract OS52I-05.

Roman, C., and H. Singh. 2005. Improved vehicle based multibeam bathymetry using sub-mapping and SLAM. IEEE Intelligent Robotics and Systems (IROS), doi: 10.1109/ IROS.2005.1545340.

Shank, T., D. Fornari, D.R. Yoerger, S. Humphris, A.M. Bradley, S. Hammond, J. Lupton, D. Scheirer, R. Collier, A.-L. Reysenbach, K. Ding, W. Seyfried, D. Butterfield, E. Olson, M. Lilley, N. Ward, and J. Eisen. 2003. Deep submergence synergy-Alvin and ABE Explore the Galápagos Rift at $86^{\circ} \mathrm{W}$, Eos, Transactions, American Geophysical Union 84(41):425.

Yoerger, D.R., M. Jakuba, A.M. Bradley, and B. Bingham. 2007. Techniques for Deep Sea Near Bottom Survey Using an Autonomous Underwater Vehicle. International Journal of Robotics Research 26(1):41-54, doi: $10.1177 / 0278364907073773$ 